\title{
International Journal of
}

\section{Business Strategies \\ (IJBS)}

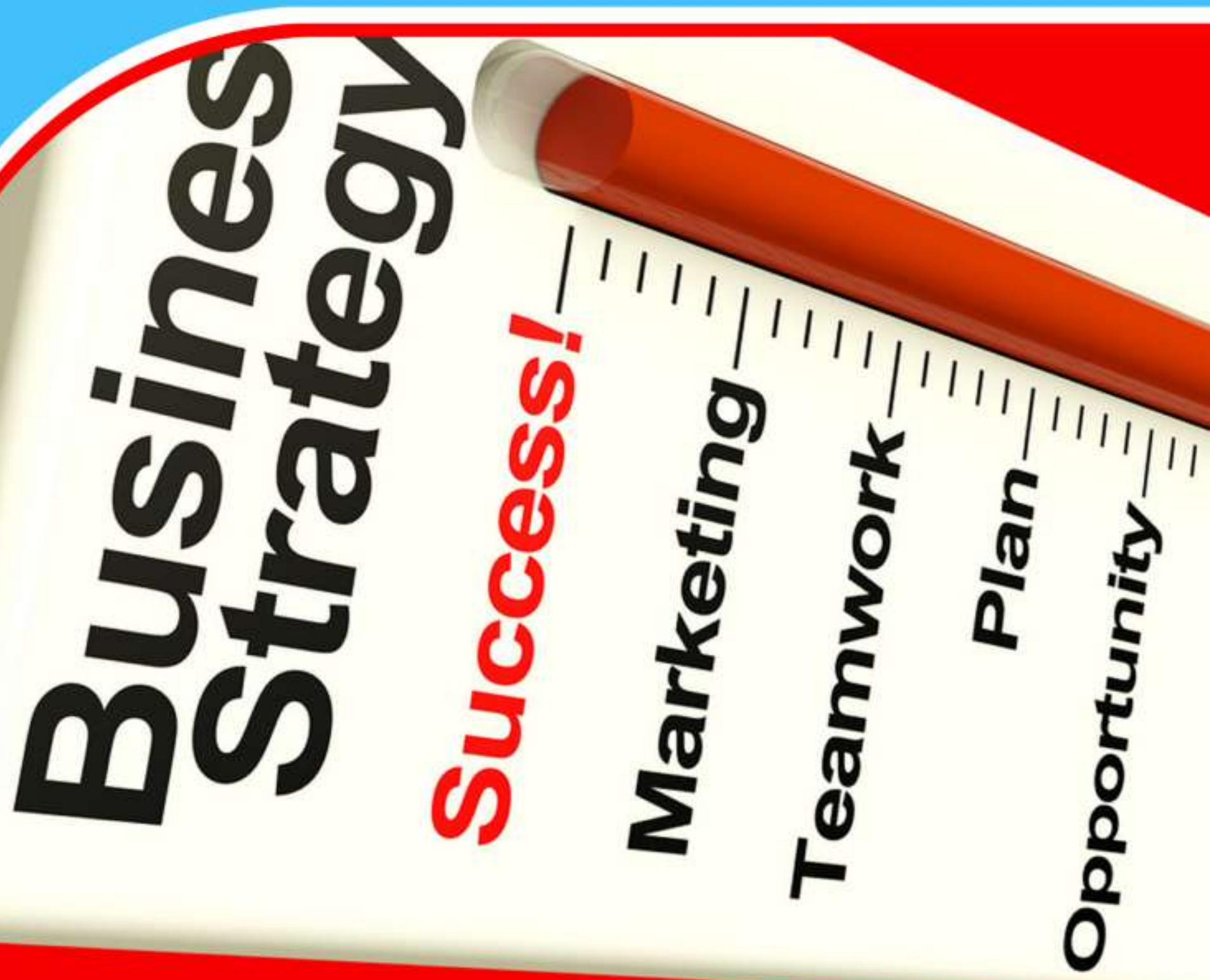

Working Capital Management and Financial

Performance of Private Hospitals in Western Uganda:

The Mediating Effect of Competitive Advantage.

Muhindo Cranimar

Rwakihembo John 


\title{
Working Capital Management and Financial Performance of Private Hospitals in Western Uganda: The Mediating Effect of Competitive Advantage.
}

\author{
Muhindo Cranimar \\ Mountains of the Moon University, \\ School of Business and Management Studies \\ Email: muhcranmer12@gmail.com \\ Rwakihembo John \\ Mountains of the Moon University, \\ School of Business and Management Studies \\ Email: jrwakihembo.jr@gmail.com
}

\begin{abstract}
Purpose: This study aimed at examining the mediating effect of competitive advantage in the relationship between working capital management (WCM) and the financial performance of private hospitals in Western Uganda.

Methodology: The study adopted a positivist approach and a cross-sectional research design to collect data from 32 Private hospitals in Western Uganda. A closed-ended questionnaire was used to collect data from hospital administrators, accountants, storekeepers and pharmacists in private hospitals who were purposively selected. Hierarchical multiple regression was used for data analysis.

Findings: Results indicate that competitive advantage is a significant mediator in the relationship between working capital management and private hospitals' financial performance in Western Uganda.

Unique Contribution to practice and policy: The study has deep-rooted the urgent need for private hospitals to adopt more innovative strategies to attain a competitive edge and hence superior financial performance. However, the study was positivistic, thus subject to methods bias that could have affected the results' validity.
\end{abstract}

Keywords: Working Capital Management, Competitive advantage, financial performance 


\section{Introduction}

Working capital management (WCM) involves planning and controlling current assets and current liabilities to reduce the risk of failure to meet daily obligations and avoid excessive investment in these assets (Nyabwanga et al., 2012). On the other hand, financial performance is a measure of how financial objectives have been accomplished in an organisation (Padachi, 2016). According to the Corporate Finance Institute (2019), competitive advantage is an attribute that enables a company to outperform its competitors. This allows a company to achieve superior margins compared to its competition and generates value for its stakeholders. Therefore, this study advances the understanding of the mediating effect of competitive advantage in the WCMfinancial performance matrix among private hospitals in Western Uganda.

The financial performance of businesses continues to attract significant attention of academicians and policymakers across the globe due to its severe implications to any given organisation's ultimate survival (Kamukama et al., 2017; Orobia et al., 2013). Financial performance reflects a firm's ability to operate efficiently, profitably, grow, survive, and react to environmental opportunities and threats (Kamukama et al., 2017). In Africa, several businesses have collapsed, with poor financial performance cited as one of the leading causes of the collapse (Orobia et al., 2020). Specifically, in Uganda, businesses' poor financial performance is evident where $30 \%$ of companies do not survive beyond three years (Afunadula, 2018).

Similarly, Uganda's health sector is not unique to poor financial performance challenges, with private hospitals affected the most (Ministry of Health (MOH), 2018). The Compuscan (Credit bureau and information services provider in Uganda) credit bureau assessment of the health sector for the period 2017-2019 indicated that, private hospitals performed worse in financial performance compared with the banking sector's small and medium-sized enterprises (SMEs) lending portfolio (Banyan, 2019). The value of defaulted loans by the health sector was $3 \%$ of Ugx 150 Billion in 2017 and $4 \%$ of Ugx 222 Billion in 2019 compared to the $2.5 \%$ of Ugx 285 Billion in 2017 and $2.8 \%-3.5 \%$ of Ugx 458 Billion in 2019 of outstanding loan balances due to the small and medium enterprises (SMEs) (Banyan, 2019). Private Hospitals' failure from meeting the debt obligations from financial institutions is an indicator that they face challenges in managing their working capital than their counterpart SMEs (Ssendagire, 2018).

Earlier scholars linked private hospitals' financial performance to working capital management (Wirda et al., 2019; Rochmadhona et al., 2018; Daud et al., 2010). It is argued that organisations must manage working capital to keep their business operations running while maintaining the agility to support their businesses' strategic goals and growth objectives (Wanjiru et al., 2019). WCM optimisation is key to assuring that a company can maintain production/service delivery, cover the cost of wages and supplies, and has enough liquidity to service short-term credit obligations (Fellers, 2019). Fellers further opined that the old days of simply managing working capital by deferring payments to vendors and accelerating customer collections are not so easy anymore. In today's globally diverse organisations with complex supply chains and dynamically changing markets, management needs better tools for seeing the big picture and drilling down into working capital details across individual business units (Wanjiru et al., 2019). Only by seeing the complete picture can companies optimise working capital both locally and globally while bearing 
in mind the importance of all supplier and customer relationships. This is the gist towards competitive advantage (Rochmadhona et al., 2018 and Fellers, 2019).

Porter (1985) argued that the low-cost leaders usually excel in performance since, in most cases, they possess unique capabilities that include the supply of scarce raw materials, high degree of capitalisation, and dominance of production/service technology (Wanjiru et al., 2019). Wheelen and Hunger (2012) suggested that a firm that is a cost leader gains a competitive advantage by offering its products/services at lower prices than the competitors. This study was premised on the resource-based view (RBV) theory. As coined by Barney in 1991, the RBV suggests that a firm's superior performance is a function of its resources and its capability to convert these resources to provide sustainable competitive advantage (Barney, 1991). These resources include all assets, capabilities, organisational processes, firm attributes, information, knowledge, etc., that a firm uses to devise and implement its plans to improve its efficiency and effectiveness (Orobia et al., 2020).

Barney (1991) categorises resources into tangible resources (physical resources) and intangible resources (nonphysical resources). The fundamental assumptions of the RBV are that: (1) resources are distributed heterogeneously across firms, and (2) heterogeneity across firms can be long-lasting since the productive resources cannot be transferred from firm to firm without costs. The proponents of the RBV posited that a firm's resources could provide sustainable performance if they are valuable, rare, inimitable and non-substitutable. Congruently, the relevance of RBV to this study resides in its preposition that sustainable firm performance is contingent on a business's unique offerings and capabilities and the development of this uniqueness over time by nurturing the firm's core competencies. This study posits that when managers of private hospitals adopt the best working capital management practices, they will be able to translate this into an improvement in inventory management, receivables management, payables management, and cash management better than their rivals which, in turn, will lead to better financial performance.

A study by Kamukama et al. (2017) reinforced the important position of managerial competence and competitive advantage as solid predictors of commercial banks' financial performance. Similarly, Wanjiru et al. (2019) revealed that competitive advantage has a mediating effect on the relationship between WCM and manufacturing firms' financial performance in Kenya. Furthermore, an assessment by Daud et al. (2010) of the performance of small and medium enterprises (SMEs) in Asia based on 289 usable questionnaires revealed the following: (i) knowledge management influences competitive advantage positively; (ii) competitive advantage enhances firm performance; and (iii) competitive advantage is a mediator between knowledge management processes and financial performance. The research demonstrated that a company's knowledge management processes and competitive advantage could be integrated to enhance financial performance.

Another study by Rochmadhona et al. (2018) showed that WCM positively affected both financial performance and competitive advantage. The competitive advantage had a positive effect on financial performance, and there were different levels of WCM in Indonesia, Laos, Vietnam, the Philippines, and Thailand. These findings support the proposition of this study and the resourcebased (RBV) theory, which asserts that a unique set of owned and controlled resources can make the company have superior sustainable performance. Nkundabanyanga et al. (2017), in their study, 
revealed that robust financial management practices are associated with better loan performance of microfinance institutions (MFIs) in Uganda. Results also showed a significant positive relationship between the competitive advantage of the MFIs and their loan performance. Furthermore, they established a significant positive relationship between competitive advantage and loan performance. Moreover, results also showed a full mediation effect of competitive advantage on the association of financial management practices and loan performance, implying that the association of financial management practices of the MFIs on their loan performance is entirely through their competitive advantage.

Additionally, Wirda et al. (2019) set out to determine the influence of entrepreneurial competency on business performance with competitive advantage as a mediating variable. They sampled 213 business managers of the creative industry in the craft sector in West Sumatra-Indonesia. Data were collected through questionnaires and analysed by Structural Equation Modeling (SEM) using AMOS software. Results showed that entrepreneurial competency has a positive and significant effect on business performance, entrepreneurial competency has a positive and significant effect on competitive advantage, competitive advantage has a positive and significant effect on business performance, and competitive advantage posed a mediating effect in entrepreneurial competency and business performance relationship.

Given the extant literature, there is no single study addressing the mediating effect of competitive advantage in the relationship between WCM and private hospitals' financial performance in Uganda. Besides relying on developed countries such as Indonesia (Rochmadhona et al., 2018), extant studies have addressed other predictor variables such as managerial competencies (Kamukama et al., 2017), knowledge management (Daud et al., 2010), and entrepreneurial competency (Wirda, 2019) among others, thus ignoring the role of working capital management. Moreover, studies have mainly concentrated on other types of organisations such as commercial banks (Kamukama et al., 2017) and manufacturing firms (Wanjiru et al., 2019), MFIs (Nkundabanyanga et al., 2017) etc., hence leaving the literature on the financial performance of private hospitals largely unexplored. Therefore, the present study was urgent as it set out to explore the mediating effect of competitive advantage in the relationship between working capital management and private hospitals' financial performance in the context of Uganda- a developing country. It was thus hypothesised that

$H_{1:}$ Competitive advantage mediates the association between WCM and financial performance of private hospitals

\section{Methodology}

\section{Research Paradigm, Design, Population, Sample and Sampling Procedure}

The study employed a positivist paradigm, collecting and analysing quantitative data through scientific procedures. This enabled the generalisation of results and maintained the researcher and participants (Zuckweiler et al., 2016). A cross-sectional study design was followed, with data obtained at a single point in time on more than one case, to detect patterns between variables (Bell et al., 2018). Given a population of 35 private hospitals in Western Uganda (MOH, 2018), 32 hospitals formed the unit of analysis. This was determined using Krejcie and Morgan's table 
(Krejcie and Morgan, 1970). Emphasis was on Western Uganda since it is the leading region with challenges in the financial performance of private hospitals in Uganda (UCMB, 2018).

The researcher first categorised private hospitals by districts using stratified sampling and then randomly selected them from each district using simple random sampling to minimise the sampling bias (Lavrakas, 2020). Respondents were segregated into four mutually exclusive categories. These respondents per hospital included Hospital administrator, Accountant, storekeeper, and pharmacist. Respondents were purposively selected based on their technical knowledge about the study's purpose and their direct involvement with working capital management (Mulajje, 2019). The study used a self-administered questionnaire as a data collection instrument. A selfadministered questionnaire was desirable as it discloses direct feedback from the respondents and allows anonymity of feedback (Lewis et al., 2020). All private hospitals returned questionnaires, thus achieving a response rate of $100 \%$.

\section{Measurement of Variables and the Questionnaire}

WCM was measured in terms of accounts payable management, accounts receivable management, cash management, and inventory management (Nyabwanga et al., 2012). Competitive advantage covered cost leadership, focus, and differentiation strategies (Porter, 1985). Additionally, financial performance was measured in terms of profitability (return on assets and return on equity), liquidity, and solvency ratios (Kamukama et al., 2017). Besides, all variables were anchored on a five (5) point Likert scale (Liker Mcleod, 2019). The scale ranges from 1 (Strongly disagree) to 5 (Strongly agree). A 5-point Likert scale enabled the study to get a holistic view of people's perceptions and their level of agreement or disagreement on particular statements (Mcleod, 2019).

\section{Control for Common Methods Bias}

Cognizant of the negative effect of common methods bias (CMB) in questionnaire-based studies in social sciences (Field, 2006), the study controlled for CMB to avoid false internal consistency. First, multiple scales were used for perceptive, independent and mediator constructs. Second, the respondent's anonymity was protected so that their responses were more aligned to the purpose of the study. Lastly, respondents were expressly assured that there are no right or wrong answers as long as the responses are honest. This aimed at reducing the respondent's apprehension over their responses hence reducing the possibility of editing their answers to give what they perceive as the best answers (Orobia et al., 2020).

Consequently, in line with Podsakoff et al. (2003), the study ran Herman's single factor test in SPSS V.22 to confirm the presence or absence of common methods bias. All study variables were loaded into factor analysis, and the unrotated component matrix was observed. As noted by Hartman et al. (2010), the rule is that no single component should account for more than $50 \%$ of the total variance. This condition was met as all study variables accounted for less than $50 \%$ hence confirming the absence of bias in responses.

\section{Reliability and Validity}

The Cronbach's alpha coefficients were computed using SPSSv22. All constructs met the threshold of 0.7 hence indicating the questionnaire's acceptable reliability (Mohsen and Dennick, 2011). Content validity was also confirmed, considering that all variables yielded a content validity index 
(CVI) above the cutoff point of 0.7 (Lawshe, 1975 and Amin, 2005). Additionally, construct validity was also confirmed given that average variance (AV) from the exploratory factor analysis (EFA) was above 0.7 and average variance extracted (AVE) was above 0.5 for all constructs (Middleton, 2016) hence confirming convergent and discriminant validity, respectively.

\section{Data Analysis}

The study tested and confirmed parametric assumptions of normality, linearity, homogeneity of variance, and multi-collinearity as per the recommendations of Field (2006) and Tabachnick and Fidell (2001). Congruently, hierarchical multiple regression was used in testing the mediating effect of competitive advantage in the relationship between working capital management and financial performance (Tabachnick and Fidell, 2001). Assumptions of Baron and Kenny (1986) for mediation were all tested and found tenable. Baron and Kenny (1986) recommended that for a mediation to be deemed existent, there should be a relationship between the independent and dependent variables, independent and the mediator variables, mediator and dependent variables, and finally while controlling for the mediator variable, the effect of the independent on the dependent variable should reduce. Consequently, the following analytical regression models for testing the mediating effect of competitive advantage in the relationship between working capital management and financial performance were defined.

$\mathrm{FP}=\mathrm{b}_{0}+\mathrm{b}_{1} \mathrm{WCM}+\mathrm{e} \ldots \ldots \ldots \ldots \ldots \ldots \ldots \ldots \ldots \ldots \ldots \ldots \ldots \ldots \ldots \ldots$

$\mathrm{FP}=\mathrm{b}_{0}+\mathrm{b}_{1} \mathrm{WCM}+\mathrm{b}_{2} \mathrm{CA}+\mathrm{e} \ldots \ldots \ldots \ldots \ldots \ldots \ldots \ldots \ldots$ ii

Where FP = Financial performance, $b_{0}$ constant, $b_{1}$ WCM, coefficient of working capital management, $b_{1} C A$, coefficient of competitive advantage, and $\mathrm{e}=$ error term.

\section{Results}

\section{Hierarchical Multiple Regression Results}

Table 1: Mediation Effect of Competitive Advantage

\begin{tabular}{lrr}
\hline & $\begin{array}{r}\text { Model 1 } \\
\text { (Before }\end{array}$ & $\begin{array}{r}\text { Model 2 } \\
\text { Mediation) }\end{array}$ \\
\hline Beta & $\begin{array}{r}\text { Bfter Mediation) } \\
\text { Beta }\end{array}$ \\
\hline Working Capital Management & $0.57^{* * *}$ & $0.36^{* * *}$ \\
Competitive Advantage & & $0.17^{* * *}$ \\
Model Summary & & \\
R & & 0.69 \\
R-Square & 0.57 & 0.48 \\
R-Square change & 0.32 & 0.16 \\
Sig. R-Square change & - & 0.001 \\
Sig (ANOVA) & 0.001 & 0.001 \\
\hline$* *$ P< 0.01 level (1-tailed), $\mathrm{n}=32$ & 0.001 & \\
Dependent Variable: Financial Performance & &
\end{tabular}


The hierarchical regression analysis (Table 1) revealed that WCM significantly influenced financial performance $(\beta=.57, p<.001)$ in model 1 . This means that a unit change in WCM affects financial performance by 0.57 units, accounting for $32 \%$ of the variance in financial performance. This implies that effective working capital management in terms of efficient receivables, payables, cash, and inventory management leads to an improvement in the financial performance of private hospitals in Western Uganda. In model 2, while controlling for WCM, competitive advantage exhibited a substantial positive effect on financial performance, given a beta coefficient $(\beta=.17$, $p<.01$ ), accounting for an additional $16 \%$, making a total of $48 \%$ of the predictive power of the model. This means that a unit increase in competitive advantage increases financial performance by 0.17 units. This implies that when a private hospital adopts competitive strategies such as focusing on a niche market, differentiating their services, and minimising their operational costs, they will improve their financial performance.

Additionally, with an introduction of competitive advantage (the mediator) in model 2, the effect of WCM on financial performance decreased substantially from $(\beta=.57, \mathrm{p}<.001)$ to $(\beta=.36$, $p<.001$ ). However, it remained significant, thus confirming partial mediation (Jose, 2008). From these results, a ratio index revealed that $37 \%$ of the influence of WCM on financial performance was explained through competitive advantage, and 63\% of the effect was direct (Jose, 2013). Furthermore, using a bootstrap approximation in AMOS version 22 as recommended by Jose (2008), the mediation effect of competitive advantage was significantly different from zero at the $(p<.001$ two-tailed) level.

These results, indicated conformity to mediation assumptions by Baron and Kenny (1986) and supported the hypothesis that "competitive advantage mediate the relationship between WCM and financial performance of private hospitals".

\section{Discussion of Results}

The predominant theme ascending out of this study is that WCM improves the financial performance of private hospitals through competitive advantage. From the hierarchical regression results, it was observed that competitive advantage mediates the relationship between WCM and private hospitals' financial performance in Western Uganda. This means that whereas WCM can positively influence financial performance, a private hospital can achieve superior financial performance if the management harnesses their innovative capabilities through focus, differentiation, and cost leadership strategies. This will enable the private hospitals to outperform their rivals hence significantly improving financial performance. For instance, a private hospital that minimises costs is likely to increase its profitability. They will also charge less for their services than competitors hence attracting more clients. The results confirmed that WCM is not a sufficient factor in improving an organization's financial performance but rather, efforts must be exerted on adopting innovative strategies that will enhance their financial performance.

The present study results rhyme with the preposition of Porter (1985), who opined that that companies that adopt generics of superior cost leadership and differentiation enjoy a larger market share, which in turn leads to higher profitability. However, the condition is that such innovative abilities must be valuable, rare, inimitable, and exploitable by the organisation (Coleman et al., 2013). Furthermore, Porter (1985) argued that the low-cost leaders usually excel in performance 
since, in most cases, they possess unique capabilities that include the supply of scarce goods and services, high degree of capitalisation, and dominance of production/service technology (Wanjiru et al., 2019). Similarly, Wheelen and Hunger (2012) posited that a firm that is a cost leader gains a competitive advantage by offering its products/services at lower prices than the competitors.

The study findings also resonate with the results in the prior studies. For instance, a survey by Kamukama et al. (2017) revealed that competitive advantage mediates managerial competencies and the financial performance of commercial banks in Uganda. Similarly, Wanjiru et al. (2019) demonstrated that competitive advantage has a mediating effect on the relationship between WCM and manufacturing firms' financial performance in Kenya. In a related case, a study by Daud et al. (2010) based on 289 usable questionnaires and revealed the following: (i) WCM processes influence competitive advantage positively; (ii) competitive advantage enhances firm performance; and (iii) competitive advantage is a mediator between WCM processes and financial performance. Their study demonstrated that WCM processes and competitive advantage can be integrated to enhance firm performance. Additionally, Nkundabanyanga et al (2017) in their study revealed a full mediation effect of competitive advantage on the association of financial management practices and loan performance among MFIs in Uganda. This implies that the association of financial management practices of the MFIs on their loan performance is entirely through their competitive advantage.

Besides, results also support the assumptions of the RBV theory which is a strategy for achieving competitive advantage (Barney, 1991). The theory's core idea is that an organisation should harness its capabilities and resources already available (Ssendagire, 2018). For example, private hospitals can devise stringent cash internal control systems, effectively manage trade creditors, inventory control checks, among others, rather than having to acquire new skills, traits, or functions for each different opportunity (Tanveer et al., 2016). Barney (1991) noted that competitive advantage is dependent on the valuable, rare, and hard-to-imitate resources that reside within an organisation. The theory assumes that, even with the endowments, an organisation can only be competitive if it creates new factors to improve the existing ones (Porter, 1985). According to Porter (1985), the more complex and dynamic the country's economic environment is, the higher the chances that firms will fail if they cannot create a robust competitive advantage.

\section{Conclusion}

This study aimed at exploring the mediating effect of competitive advantage in the WCM-financial performance matrix among private hospitals in Western Uganda. It has been deduced from the study results that competitive advantage mediates the relationship between WCM and financial performance among private hospitals in Western. These results imply that hospital administrators need to be innovative and acquire more relevant capabilities for copying up with the stiff competition, as emphasised by the RBV theory.

\section{Implications}

This study's findings have important implications for academics, practitioners, and regulators. Academics now recognise that competitive advantage mediates the relationship between WCM and financial performance among private hospitals, unlike in the past, where literature was scanty. 
The administrators and owners of private hospitals now appreciate the significance of adopting competitive strategies in their operations. The study has indicated that being innovative in the health sector helps aids WCM practices to improve financial performance. The owners and managers of private hospitals need to be pro-active and adopt better working capital management practices that can consequently enhance private hospitals' financial performance through competitive advantage. Through the Ministry of Health, the Government should mandate hospital administrators to acquire relevant skills for managing working capital. This may be achieved through developing policies that aim at empowering managers and owners of private hospitals to obtain more innovative knowledge and skills that are critical for their competitiveness hence improving their financial performance.

\section{Study limitations}

This study is not without limitations that form avenues for future research. The extant literature is short of studies on the mediating effect of competitive advantage in the relationship between WCM and private hospitals' financial performance. This limited study from cross-validating the findings on mediation. Studies should be conducted to confirm these results. This study employed only a positivist paradigm. Future research could use triangulation to compare findings. Finally, this study only considers financial performance and neglects private hospitals' nonfinancial performance, thus being limited in terms of conceptual scope. It is essential that there are studies on nonfinancial performance using evidence from Uganda. Besides, having relied on a cross-sectional research design, the study was deprived of the opportunity to analyse financial trends as a function of WCM through competitive advantage. Besides, people's perceptions change over time. Thus future studies could avert this by conducting longitudinal studies. Nevertheless, the study contributes to financial performance studies by documenting evidence of the mediating role of competitive advantage in the relationship between WCM and financial performance among private hospitals in the context of Uganda. 


\section{References}

Afunadula, B. (2018), “Current mortality rate of SMEs Will Kill private sector - economist warns", PML Daily, available at: www.pmldaily.com/business/2018/05/current-mortalityrate-of-smeswillkill-private-sector-economist-warns.html (accessed 18 March 2021).

Banyan (2019) Financial Management Practices And Business Performance Of Small And Medium Enterprises in Western Uganda (2019). Credit reference bureau (COMPUSCAN).

Barney, J. (1991), "Firm resources and sustained competitive advantage," Journal of Journal of Management, Vol. 17 No. 1, pp. 99-120.

Baron, R. M., and Kenny, D. A. (1986). The moderator-mediator variable distinction in Social-psychological research. Strategic, Conceptual, and statistical considerations. The Journal of Personality and Social Psychology, 51(1173-1182).

Coleman, S.(2013). Competitive Advantage Achievement Through Innovation And Knowledge. Journal Of Competitiveness, 5, 82-96, 2013., 82-89.

Daud, S. et al. (2010). Knowledge Management And Firm Performance In SMEs: The Role Of Social Capital As A Mediating Variable. Asian Academy Of Management Journal Vol. 15, No. 2, 135-155, July 2010, 135-155.

Fellers, D. (2019, September 23). Digitalist Magazine. Retrieved September 06, 2020, From

Digitalised website: Https:/Www.Digitalistmag.Com/Finance/2019/09/23/WorkingCapital-Management-Exploring-What-Why-And-How-06200702/.

Field, A. (2006), Discovering Statistics Using SPSS (2nd Edition), Sage, London HarperCollins.

Hartman, N., Williams, L. J., and Cavazotte, F. (2010), Common Method variance and marker variables: A review and comprehensive CFA-marker technique. Organizational Research Methods, 13 (3), 477-514.

Institute, C. F. (2019, March 22). Corporate Finance Institute. Retrieved September 21, 2020, From Corporate Finance Institute Website:

Https://Corporatefinanceinstitute.Com/Resources/Knowledge/Finance/CashManagement/

Jose E.P (2013). Doing Statistical Mediation and Moderation. New York: NY: Guildford Press.

Jose, E.P. (2008). Welcome to the Moderation/Mediation Help Centre. School of Psychology Victoria University of Wellington.

Kamukama, N., Kyomuhangi, S.D., Akisimire, R. and Orobia, L.A. (2017), "Competitive advantage: mediator of managerial competence and financial performance of commercial banks in Uganda", African Journal of Economic and Management Studies, Vol. 8 No. 2, pp. 221-234. 
International Journal of Business Strategies

ISSN 2519-0857 (online)

Vol.6, Issue 1, pp $12-23,2021$

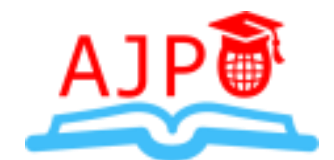

www.ajpojournals.org

Lavrakas, P. (2020). Sage Research Methods. Retrieved September 19, 2020, From Sage Research Methods Website: Https://Methods.Sagepub.Com/Reference/Encyclopedia-Of-SurveyResearch-Methods/N516.Xml Management, Vol. 17 No. 1, pp. 99-120.

Managerial competence and financial performance of small businesses. Journal of Accounting in Emerging Economies. Emerald Publishing Limited. 2042-1168.DOI 10.1108/JAEE-072019-0147.

Mcleod, S. (2019, August 23). Simply Psychology. Retrieved September 06, 2020, From Simply Psychology Website: Https://Www.Simplypsychology.Org/Likert-Scale.Html.

Ministry Of Health. A master list of all health facilities in Uganda by the end of 2018. Health Facilities Inventory Uganda 2018.

Mohsen and Dennick (2011) A Factor Analysis Methodology For Analysing The Factors That Contribute To Economic Development In The State Of Tennessee. Trace: Tennessee Research And Creative Exchange, 1-105.

Mulajje, M. (2019). Working Capital Management And Financial Performance Of Small And Medium Enterprises In Kampala Capital City Authority: A Case Study Of Kawempe Division Urban Council. Kampala: Kyambogo University Library.

Nkundabanyanga, S. et al. (2017). Impact Of Financial Managament Pratices And Competitive Advantage On The Loan Performance Of Micro Finance Institutions. International Journal Of Social Economics: Vol 44;Issue 1; Sn 0306-8292;Do 10.1108/Ijse-204-0104, 114-131.

Nyabwanga R et al. (2012). Effect Of Working Capital Management Practices On Financial Performance: A Study Of Small Scale Enterprises In Kisii South District, Kenya. African Journal Of Business Management Vol. 6(18), Pp. 5807-5817, May 09, 2012, 60-78.

Orobia. L. A. and Nakibuuka.J, Bananuka. J and Akisimire. R (2020), Inventory management, managerial competence and financial performance of small businesses. Journal of Accounting in Emerging Economies. Emerald Publishing Limited. 2042-1168.DOI 10.1108/JAEE-07-2019-0147.

Padachi, K., Narasimhan, S. M., Durbarry, R., \& Howorth, C. (2016). An Analysis of Working Capital Structure and Financing Pattern of Mauritian Small Manufacturing Firms. Journal of Applied Finance, 14, 41-62.

Podsakoff, P.M., Mackenzie, S.B. and Lee, J.Y. (2003), Common Method Bias in Behavioral Research: A Review of Literature and Recommended Remedies, Journal of Psychology, 88(5), 879-903.

Rochmadhona, B. et al. (2018). The Competitive Advantage Between Intellectual Capital And Financial Performance Of Banking Sector In Asian Countries. Jurnal Keuangan Dan Perbankan, 22(2):321-334, 2018, 321-334

Ssendangire, D. L (2018). Working Capital Level, Working Capital Financing Approaches, Firm Size Nd Profitability Of Manufacturing Firms In Uganda. Nairobi: University Of Nairobi. 
Tabachnick B. G., and Fidell. L.S. (2001), Using Multivariate Statistics, $4^{\text {th }}$ Edition, New York, HarperCollins.

Tanveer Bagh Et.Al. (2016). The Impact Of Working Capital Management On Firms Financial performance: Evidence From Pakistan. International Journal Of Economics And Financial Issues, 2016, 6(3), 1097-1105., 1097-1105.

Uganda Catholic Medical Bureau. An assessment of the performance of private not-for-profit health facilities 2018.

Wanjiru, A. et al. (2019). The Mediating Effect Of Competitive Advantage On The Relationship Between Corporate Strategies And Performance Of Manufacturing Firms In Nairobi City County, Kenya. Iosr Journal Of Business And Management (Iosr-Jbm); E-Issn: 2278487x, P-Issn: 2319-7668. Volume 21, Issue 4. Ser. I (April. 2019), Pp 07-15, 7-15.

Wheelen and Hunger (2012) International Journal Of Academic Research In Business And Social Sciences May 2012, Vol. 5, No. 5issn: 2222-6990. Role Of Inventory Management On Competitiveadvantage Among Manufacturing Firms In Kenya: A case Study Of Unga Group Limited, 88-104.

Wirda. F, PolytechnicHerri. P.S, Rivai. H. A (2019). Competitive Advantage: Mediation Effect Between Entrepreneurial Competency and Business Performance Creative Industries in West Sumatera-Indonesia.

Zuckweiler, D. (2016). The Mediating Effect Of Competitive Advantage On The Relationship Between Corporate Strategies And Performance Of Manufacturing Firms In Nairobi City County, Kenya. Iosr Journal Of Business And Management (Iosr-Jbm); E-Issn: 2278487x, P-Issn: 2319-7668. Volume 21, Issue 4. Ser. I (April. 2019), Pp 07-15, 7-15. 